\title{
Probiotic supplementation affects the glycan composition of mucins secreted by Brunner's glands of the pig duodenum ${ }^{\text {is }}$
}

\author{
Gianluca Accogli ${ }^{a}$, Alberto Maria Crovace ${ }^{\mathrm{b}}$, Maria Mastrodonato ${ }^{\mathrm{c}}$, Giacomo Rossi $^{\mathrm{d}}$, \\ Edda G. Francioso ${ }^{\mathrm{a}}$, Salvatore Desantis ${ }^{\mathrm{a}, *}$ \\ a Section of Veterinary Clinics and Animal Productions, Department of Emergency and Organ Transplantation (DETO), University of Bari Aldo Moro, S.P. \\ Casamassima Km 3, 70010 Valenzano, Bari, Italy \\ ${ }^{\mathrm{b}}$ Dottorato di Ricerca in Sanità e Scienze Sperimentali Veterinarie, University of Perugia, Perugia, Italy \\ " Department of Biology, University of Bari “Aldo Moro", Via E. Orabona 4, 70124 Bari, Italy \\ d School of Biosciences and Veterinary Medicine, University of Camerino, Via Circonvallazione 93/95, 62024 Matelica, MC, Italy
}

\section{A R T I C L E I N F O}

\section{Article history:}

Received 24 October 2017

Received in revised form 21 March 2018

Accepted 29 March 2018

\section{Keywords:}

Mucins

Glycohistochemistry

Lectins

Probiotics

Diet

Swine

\begin{abstract}
A B S T R A C T
The effect of a dietary probiotic blend on the carbohydrate composition of mucins secreted by the Brunner's glands in the duodenum of growing-finishing pigs was investigated by means of conventional (periodic acid-Schiff, Alcian Blue pH 2.5, high iron diamine staining) and lectin (15 lectins) histochemistry. Pigs were assigned to two dietary treatments: a control basal diet without the probiotic blend (No-Pro) and a test diet that included the probiotic blend (Pro). Duodenal tissue fragments were fixed in $4 \%$ phosphate-buffered-saline-buffered paraformaldehyde, dehydrated through a graded alcohol series, and embedded in paraffin wax. The secretory cells of the Brunner's glands from No-Pro pigs primarily produced neutral glycoproteins and a small amount of acidic non-sulphated mucins. This glycan pattern was opposite that of the Brunner's glands from Pro animals. A comparison of lectin-binding profiles of the secretory cells of Brunner's glands in these two groups showed that in Pro pigs, there was (i) a decrease in $\mathrm{N}$-linked glycans containing $\alpha 1$,2-linked fucose (Con A, UEA I); (ii) a loss of complex types of $\mathrm{N}$-glycans (PHA-L, PHA-E) terminating with lactosamine $\left(\mathrm{RCA}_{120}\right), \alpha 1,6$ - and $\alpha 1,3$-linked fucose (LTA), and $\alpha$-galactose (GSA I- $B_{4}$ ), as well as of $O$-glycans with terminal Gal $\beta 1,3 \mathrm{GalNAc}$ (PNA); and (iii) an increase in $O$-glycans containing GalNAc HPA. No-Pro and Pro samples showed no change in the expression of $\alpha 2,6$ sialoglycans and terminal GlcNAc residues and no affinity for MAL II, DBA, and SBA. These results indicate that probiotic supplementation affects the glycan composition of mucins produced in the Brunner's glands of growing-finishing pigs. These changes could effectively act on the gastrointestinal function and health status of these animals because the probiotic blend induced higher growth performance and meat quality in the test probiotic group than it did in the control basal diet group (Tufarelli et al., 2017).
\end{abstract}

(c) 2018 Elsevier $\mathrm{GmbH}$. All rights reserved.

\section{Introduction}

Brunner's glands, or duodenal glands, are specific to mammals and are located in the submucosa of the duodenal wall, although they can be found, even if discontinuously, in the jejunum of big herbivores and pigs (Krause, 2000). Brunner's glands are mucin-secreting tubulo-alveolar glands. Mucins constitute a family of densely glycosylated proteins, the high glycosylation giving them gel-like properties and the ability to resist proteolysis and hold water (Perez-Vilar and Hill, 1999). The highly viscous mucus

\footnotetext{
is This paper belongs to the special issue Animal Anatomy III.

* Corresponding author.

E-mail address: salvatore.desantis@uniba.it (S. Desantis).
}

secreted by Brunner's glands protects the underlying mucosa from mechanical insults, neutralizes the acidity of gastric juice (Florey and Harding, 1933), modulates absorption of ingesta, inhibits attack by pathogens, and maintains bacterial microflora (Krause, 2000; Flemstrom and Isenberg, 2001).

The importance of the intestinal microbiota for gastrointestinal function and health has been shown in many studies (Heinritz et al., 2013; Büsing and Zeyner, 2015; Hu et al., 2015; Liu et al., 2017). In particular, probiotics have a stimulating effect on the digestive processes and immunity of animals (Fuller, 2006; Meng et al., 2010). Therefore, their use is suggested as an alternative to antibiotics or anti-inflammatory drugs. However, the mode of action of probiotics is poorly understood and the reported mechanisms of action are often the results of in vitro experiments. These results should there- 
fore be confirmed by in vivo studies (Oelschlaeger, 2010). More recently, the use of a probiotic complex (Sivoy ${ }^{\mathrm{TM}}$, SLAB51) has been shown to enhance the growth performance and meat quality of growing-finishing pigs and to reduce pollution from animal excreta (Tufarelli et al., 2017).

Despite the physiological importance of the mucins secreted by Brunner's glands, to date nothing is known about the effects of microbiota on the composition of the mucins secreted by these glands. Previous studies have, however, demonstrated that the composition of mucins from Brunner's glands could be affected by dietary change (see Krause, 2000, for reference).

The aim of the present study was to examine the in situ effect of a dietary probiotic complex (Sivoy ${ }^{\mathrm{TM}}$, SLAB51) on the glycan composition of mucins produced in the Brunner's glands of growing-finishing pigs. We used both conventional and lectin histochemistry. The conventional technical approach discriminates neutral and acidic classes of glycoconjugates, whereas lectins allow analysis of the carbohydrate composition of complex glycans (Spicer and Schulte, 1992; Sharon and Lis, 2004). The investigation was carried out in pigs. Because of their anatomical, physiological, and genetic comparability to humans, they represent a promising animal model to determine questions of basic, applied, and translational biomedical research (Aigner et al., 2010; Stramandinoli-Zanicotti et al., 2014), including studies of human nutrition and health problems (Guilloteau et al., 2010; Verma et al., 2011; Prather et al., 2013; Gonzalez et al., 2015).

\section{Materials and methods}

\subsection{Probiotic sources}

The probiotic preparation used in the present trial was obtained from a commercial company (SLAB51, Mendes SA, Lugano, Switzerland). The probiotic SLAB51 is composed of a blend of the following strains: Streptococcus thermophiles DSM 32245, a mixture of the two strains Bifidobacterium animalis ssp. lactis DSM 32246 and DSM 32247, Lactobacillus acidophilus DSM 32241, Lactobacillus helveticus DSM 32242, Lactobacillus paracasei DSM 32243, Lactobacillus plantarum DSM 32244, and Lactobacillus brevis DSM 27961.

\subsection{Animals}

The trial received ethical approval from the Italian Ministry of Health (n.597/2015-PR del 23/06/2015) and was conducted in strict accordance with the recommendations of the Guide for the Care and Use of Laboratory Animals of the National Institutes of Health (Art. 18 D.L. 4 March 2014, no. 26).

Twenty pigs [(Landrace $\times$ Yorkshire $) \times$ Talent] with an average initial body weight (BW) of $22.80 \pm 0.95 \mathrm{~kg}$ (SE) were used in a 12 week experiment. Pigs were assigned to two dietary treatments: the control basal diet without the probiotic blend (No-Pro) and the experimental diet that included the probiotic blend (Pro). The probiotic mixture was used as a dietary supplement for the pigs during the entire feeding period at a dose of $100 \mathrm{mg} / \mathrm{kg}$ of BW. The basal diet was formulated to meet or exceed the nutrient requirements of pigs according to the NRC (1998). Pigs were housed in an environmentally controlled room with a concrete floor and were fed ad libitum.

\subsection{Sampling and histology processing}

At the end of the trial, pigs were slaughtered and specimens of duodenal tissue were immediately removed from $5 \mathrm{~cm}$ of the caudal part of the pyloric region and fixed in $4 \%(\mathrm{v} / \mathrm{v})$ phosphate-bufferedsaline-buffered paraformaldehyde for $24 \mathrm{~h}$ at $4{ }^{\circ} \mathrm{C}$. The samples were then dehydrated through a graded alcohol series and embedded in paraffin wax. Serial sections (4- $\mu \mathrm{m}$ thick) were cut and, after being de-waxed with xylene and hydrated in an ethanol series of descending concentrations, stained with hematoxylin-eosin for morphological and morphometric studies and by conventional histochemical procedures or lectin histochemistry for glycoconjugate characterization.

\subsection{Conventional histochemistry}

Sections were treated with (1) periodic acid-Schiff (PAS) reaction for neutral glycoconjugates (Mc Manus, 1948); (2) Alcian Blue $\mathrm{pH} 2.5$ (AB 2.5) for sulphate esters and carboxyl groups in glycoconjugates (Pearse, 1968); and (3) combined high iron diamine-Alcian Blue pH 2.5 (HID-AB 2.5) for simultaneous staining of sulphated (brown-black) and non-sulphated (blue) acidic glycans (Spicer, 1965). To reveal cellular combinations of both acidic and neutral glycoconjugates, we performed AB 2.5/PAS and HID/AB 2.5 staining sequences.

\subsection{Lectin histochemistry}

The binding of 15 lectins was tested to investigate the composition and distribution of oligosaccharidic chains in the Brunner's glands of the pigs (Table 1). All lectins were purchased from Vector Laboratories Inc. (Burlingame, CA, USA).

Tissue sections stained with fluorescent lectins were rinsed in $0.05 \mathrm{M}$ Tris-HCl-buffered saline (TBS) pH 7.4 and incubated in appropriate dilutions of each lectin diluted in TBS (Table 1 ) for $1 \mathrm{~h}$ at RT in the dark. After three rinses in TBS, slides were mounted in Vectashield mounting medium (Vector Laboratories, Burlingame, CA, USA). Tissue sections stained with biotinylated MAL II were immersed in $3 \% \mathrm{v} / \mathrm{v}$ solution of $\mathrm{H}_{2} \mathrm{O}_{2}$ in methanol for 10 min to suppress the endogenous peroxidase activity, rinsed in TBS pH 7.4, and incubated in a lectin solution $(25 \mu \mathrm{g} / \mathrm{ml}$ for $1 \mathrm{~h}$ at RT in the dark). After three rinses in TBS, the sections were treated with streptavidin/peroxidase complex for $30 \mathrm{~min}$ and subsequently with $0.05 \%$ (w/v) 3,3-diaminobenzidine (Vector Laboratories, Burlingame, CA, USA) plus $0.003 \%(\mathrm{v} / \mathrm{v}) \mathrm{H}_{2} \mathrm{O}_{2}$ in $0.05 \mathrm{M}$ TBS ( $\mathrm{pH} 7.6$ ) for $10 \mathrm{~min}$. Sections were dehydrated and mounted using Eukitt.

Each experiment was repeated twice for each sample. Controls for lectin staining included (1) substitution of the substrate medium with buffer without lectin and (2) incubation with each lectin in the presence of its hapten sugar (0.5 M in TBS). All control experiments gave negative reactions. Slides were observed with the light photomicroscope Eclipse Ni-U (Nikon, Japan) at 20× magnification and photographed with a digital camera (DS-U3, Nikon, Japan). The images were analyzed by the image-analyzing program NIS Elements BR (Version 4.20) (Nikon, Japan).

\subsection{Morphometry and statistical analysis}

The diameter of Brunner's gland adenomeres from both No-Pro and Pro samples was measured on 15 microphotographic fields casually detected and photographed with a digital camera (DS-U3, Nikon, Japan) connected to the light photomicroscope Eclipse Ni$\mathrm{U}$ (Nikon, Japan), using a $20 \times$ lens. Images were analyzed by the image-analyzing program NIS Elements BR (Vers. 4.30) (Nikon, JP). Each field surface was $140,000 \mu \mathrm{m}^{2}$. We measured the diameter of 450 transversally cut adenomeres of Brunner's gland from the No-Pro and Pro samples. Values were expressed as means $\pm \mathrm{SD}$. The results were evaluated for statistical significance by Student's t test and the compared data were considered statistically significant at $\mathrm{p}$ values of $<0.01$. 
Table 1

Lectins used, their sugar specificities, and the inhibitory sugars used in control experiments.

\begin{tabular}{|c|c|c|c|c|}
\hline Lectin abbreviation & \multicolumn{2}{|l|}{ Source of lectin $(\mu \mathrm{g} / \mathrm{ml})$} & \multirow{2}{*}{$\begin{array}{l}\text { Sugar specificity } \\
\text { NeuNAc } \alpha 2,3 \text { Gal } \beta 1,3( \pm \text { NeuNAc } \alpha 2,6) \text { GalNAc }\end{array}$} & \multirow{2}{*}{$\begin{array}{l}\text { Inhibitory sugar } \\
\text { NeuNAc }\end{array}$} \\
\hline MAL II ${ }^{\mathrm{a}}$ & Maackia amurensis & 25 & & \\
\hline SNA & Sambucus nigra & 15 & Neu5Ac $\alpha 2,6 \mathrm{Gal} /$ GalNAc & NeuNAc \\
\hline PNA $^{\mathrm{b}}$ & Arachis hypogaea & 25 & Gal $\beta 1,3$ GalNAc & $\beta-D-G a l$ \\
\hline $\mathrm{RCA}_{120}$ & Ricinus communis & 20 & Gal $\beta 1,4$ GlcNAc & Gal \\
\hline $\mathrm{GSA}^{\mathrm{I}-\mathrm{B}_{4}}$ & Griffonia simplicifolia & 20 & $\alpha \mathrm{Gal}$ & Gal \\
\hline DBA & Dolichos biflorus & 25 & GalNAc $\alpha 1,3($ LFuc $\alpha 1,2)$ Gal $\beta 1,3 / 4$ GlcNAc $\beta 1$ & D-GalNAc \\
\hline $\mathrm{SBA}^{\mathrm{b}}$ & Glycine max & 20 & $\alpha / \beta$ GalNAc & D-GalNAc \\
\hline HPA & Helix pomatia & 20 & $\alpha$ GalNAc & D-GalNAc \\
\hline Con A & Canavalia ensiformis & 15 & $\alpha$ Man $>\alpha$ Glc & Man \\
\hline PHA-E & Phaseolus vulgaris & 20 & Gal $\beta 1,4$ GlcNAc $\beta 1,2$ Man $\alpha 1,6$ & Man \\
\hline PHA-L & Phaseolus vulgaris & 20 & GlcNAc $\beta 1,2$ Man, triantennary complex oligosaccharides & Man \\
\hline succWGA $^{\text {b }}$ & Triticum vulgaris & 15 & BGlcNAc & D-GlcNAc \\
\hline GSA II & Griffonia simplicifolia & 20 & D-GlcNAc & D-GlcNAc \\
\hline UEA I & Ulex europaeus & 20 & L-Fuc $\alpha 1,2$ Gal $\beta 1,4$ GlcNAc $\beta$ & $\alpha$-L-Fuc \\
\hline \multirow[t]{2}{*}{ LTA } & Lotus & 25 & L-Fuc $\alpha 1,6 \mathrm{GlcNAC}$ & \\
\hline & tetragonolobus & & L-Fuc $\alpha 1,2$ Gal $\beta 1,4[$ L-Fuc1,3] GlcNAc $\beta 1,6 \mathrm{R}$ & $\alpha$-L-Fuc \\
\hline
\end{tabular}

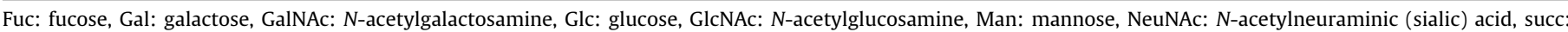
succinylated WGA.

a Biotin-labeled lectin.

b Rhodamine-labeled lectin. Non-marked lectins are fluorescein isothiocyanate-labeled lectins.

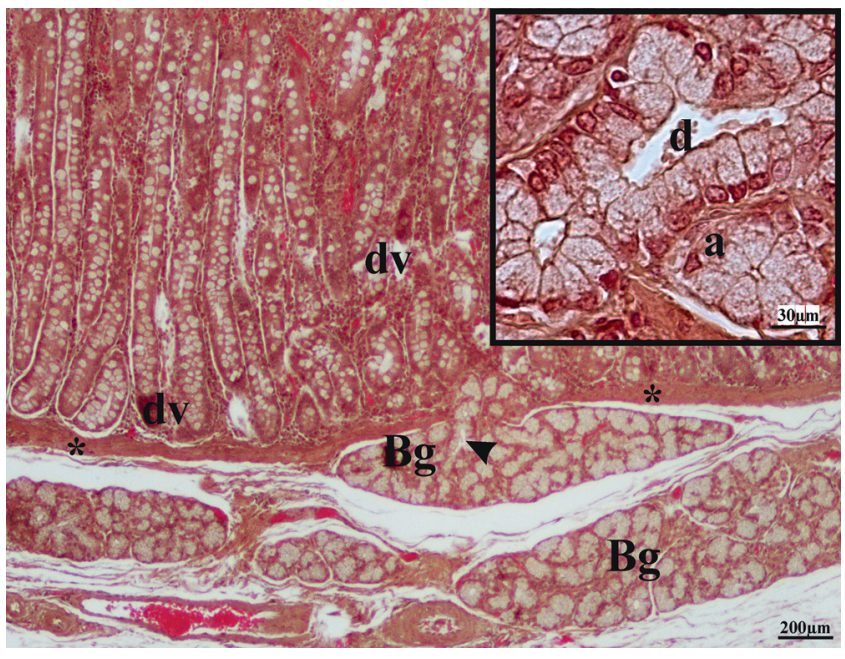

Fig. 1. Light micrograph of pig duodenum showing Brunner's glands (Bg) and duodenal villi (dv). Note the duct (arrowhead) of a Brunner's gland piercing the muscularis mucosae (asterisk) and entering the overlying duodenal mucosa. Inset displays the details of an acinous adenomere (a) and duct (d). Hematoxylin-eosin staining.

\section{Results}

\subsection{Morphology}

Swine Brunner's glands were tubulo-acinous with a main excretory duct opening at the base of the duodenal crypts (Fig. 1). Morphological analysis of Brunner's glands did not reveal significant differences between the No-Pro and Pro samples. There was also no significant difference in adenomere diameter, which measured $42.66 \pm 7.38 \mu \mathrm{m}$ in the No-Pro and $44.3 \pm 6.32 \mu \mathrm{m}$ in the Pro specimens.

\subsection{Glycohistochemistry}

The results of conventional and lectin staining patterns of Brunner's glands of both No-Pro and Pro pigs are summarized in Table 2.

The combination AB2.5/PAS procedure revealed the widespread presence of PAS-positive (magenta) cells and a few AB 2.5-positive (blue) cells in the Brunner's glands from No-Pro samples (Fig. 2A). This staining pattern was reversed in the Pro group Brunner's
Table 2

Conventional and lectin histochemistry staining pattern of the duodenal Brunner's glands of no-probiotic and probiotic-fed pigs.

\begin{tabular}{lll}
\hline & No-probiotic & Probiotic \\
\hline PAS & + & $*$ \\
Alcian Blue pH 2.5 & $*$ & ++ \\
HID & - & - \\
SNA & $+/++\mathrm{lc}$ & $+/+\mathrm{lc}$ \\
PHA-L & $+/++\mathrm{lc}$ & $-/++\mathrm{lc}$ \\
PHA-E & $\pm /++\mathrm{lc}$ & $-/ \pm \mathrm{lc}$ \\
Succinyl WGA & $-/+\mathrm{lc}$ & $-/+\mathrm{lc}$ \\
GSA II & ++ & ++ \\
Con A & ++ & + \\
UEA I & + & \pm \\
GSA I-B 4 & ++ & - \\
LTA & + & - \\
PNA & + & - \\
RCA 120 & \pm & - \\
HPA & + & ++ \\
MAL II & - & - \\
DBA & - & - \\
SBA & - & - \\
\hline
\end{tabular}

Lc: luminal content, *: few reactive cells, - : negative reaction, \pm : faintly visible reaction, + : weak positive reaction, ++ : intense positive reaction.

glands (Fig. 2B). The combination HID/AB 2.5 methods revealed the absence of HID reactivity (brown) in both Pro and No-Pro Brunner's glands (Fig. 2C,D).

Comparison of lectin reactivity in No-Pro and Pro Brunner's glands showed several different binding patterns. Except for MAL II, DBA, and SBA, which were unreactive with Brunner's glands from both No-Pro and Pro pigs, the other lectins bound the glandular cells and/or the luminal content (SNA, PHA-L, PHA-E, succinyl WGA) or only the adenomeric cells (GSA II, Con A, UEA I, GSA I-B4, LTA, PNA, $\mathrm{RCA}_{120}, \mathrm{HPA}$ ). The results are summarized in Table 2.

In particular, SNA displayed no change in the staining intensity of the secretory cells and the adenomeric luminal content of Brunner's glands from both No-Pro and Pro animals (Fig. 3A,B); PHA-L reacted with the adenomeric cells and the luminal content of NoPro Brunner's glands (Fig. 3C) and with the adenomeric luminal content of treated animals (Fig. 3D); PHA-E bound weakly with the adenomeres and strongly with their luminal content in No-Pro specimens (Fig. 3E), whereas it did not bind the adenomeres but weakly stained the luminal content of treated pigs (Fig. 3F); and succinyl WGA showed no reaction with the secretory cells, whereas it stained the luminal content in all investigated Brunner's glands (Fig. 3G,H). 


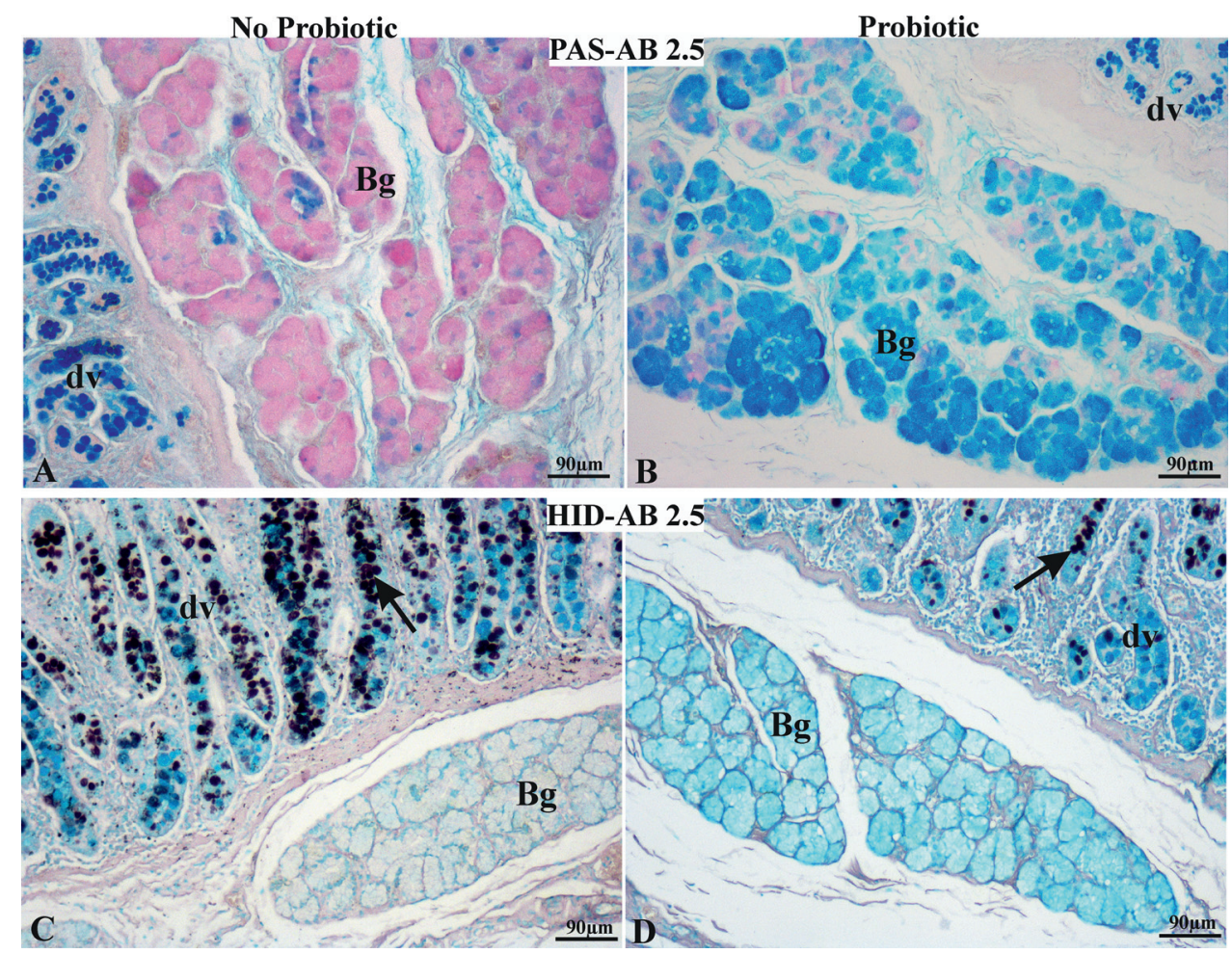

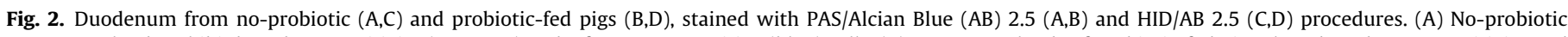

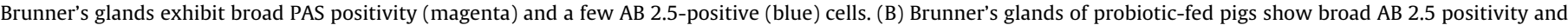

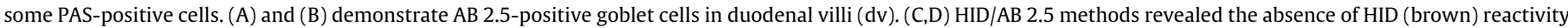

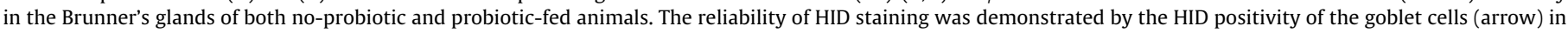
duodenal villi (dv). Bg, Brunner's gland. (For interpretation of the references to color in this figure legend, the reader is referred to the web version of this article.)

Concerning the lectins that bound only the adenomeric cells, GSA II exhibited no difference in the staining intensity between NoPro and Pro samples. Con A (Fig. 4A,B) and UEA I (Fig. 4C,D) showed stronger affinity in the No-Pro samples than in the Pro samples. GSA I- $B_{4}, \mathrm{LTA}, \mathrm{RCA}_{120}$, and PNA bound the adenomeric cells of the Brunner's glands from No-Pro pigs, whereas it did not react with the secretory epithelium of Pro Brunner's glands (Fig. 4E,F). HPA was the sole lectin showing a decrease in reactivity in the Brunner's glands of No-Pro pigs compared with that in the Brunner's glands of Pro pigs (Fig. 4G,H).

\section{Discussion}

This is the first study to demonstrate that feeding of a probiotic complex affects the glycosylation pattern of the mucins secreted by pig Brunner's glands. This investigation follows a recent report demonstrating that the use of a dietary probiotic complex (Sivoy $^{\mathrm{TM}}$, SLAB51) enhances growth performance and meat quality in growing-finishing pigs (Tufarelli et al., 2017).

Conventional histochemistry revealed that Brunner's glands of no-probiotic-fed pigs produce primarily neutral glycoproteins (PAS reaction), a small amount of acidic carboxylated mucins (AB 2.5 positivity), and no sulfoglycans (HID negativity). These results are consistent with those of previous studies on the Brunner's glands of several mammals (Krause, 2000; Verdiglione et al., 2002; Schumacher et al., 2004; Scillitani and Mentino, 2015), including young adult pigs (Takehana and Abe, 1986).

Using 15 different lectins, we characterized the carbohydrate composition of the mucins from Brunner's glands more thoroughly. The secretory epithelium of Brunner's glands from No-Pro pigs showed the presence of both $\mathrm{N}$ - and $\mathrm{O}$-linked glycans. $\mathrm{N}$-Glycans were high mannose (Con A) and complex types (PHA-L, PHA-E). O-
Glycans contained the terminal disaccharide Gal $\beta 1,3 \mathrm{GalNA}$ (PNA) and the simplest mucin $O$-glycan made by a single GalNAc linked to serine or threonine (HPA). Moreover, we observed glycans terminating with fucose (LTA, UEA I), GlcNAc (GSA II), galactose (GSA $\left.\mathrm{I}-\mathrm{B}_{4}\right)$, lactosamine $\left(\mathrm{RCA}_{120}\right)$, and Neu5Ac $\alpha 2,6 \mathrm{Gal} / \mathrm{GalNAc}(\mathrm{SNA})$. Although our results agree with previous reports on pig Brunner's glands (Takehana and Abe, 1986; Gelberg et al., 1992), our study provides a more in-depth characterization of the oligosaccharide chains of Brunner's gland glycoproteins because SNA, PHA-L, PHAE, LTA, and HPA have not been used previously. The luminal content accumulated high mannose and complex types of $\mathrm{N}$-glycans as well as glycans with internal GlcNAc (succinyl WGA) and terminal $\alpha 2,6$ linked sialic acid (SNA). The role of sugar residues in the secretory glycoproteins of Brunner's glands is not well known. However, oligosaccharide chains containing lactosamine in high mannosylated $\mathrm{N}$-glycans have been observed in the human mucin MUC6 (Toribara et al., 1997). Notably, the gene encoding the latter mucin is also expressed in human Brunner's glands (Bartman et al., 1998). Concerning sialic acid, the negative charge of this molecule has been shown to have a role in the transport of chloride, bicarbonate, water, and protons in Brunner's glands (Collaco et al., 2013). In secreted mucus, sialic acid can contribute to the viscosity and protection of the underlying epithelium from lysis by gastric juice and bacteria (Schauer, 2004) and can act as a ligand for several symbiotic and pathogenic microorganisms (Lehmann et al., 2006). GalNAc and Gal residuals can inhibit the cell binding of the trophozoites of Entamoeba histolytica, the causative agent of amoebiasis (Ralston and Petri, 2011). Regarding fucosylated residuals, they can be important in both the maintenance of the bacterial flora involved in the degradation of fucose from food (Becker and Lowe, 2003) and in increasing the viscosity of mucus (Liquori et al., 2012). O-Glycans carrying terminal $\alpha 1,4$-linked GlcNAc residues act both as a nat- 

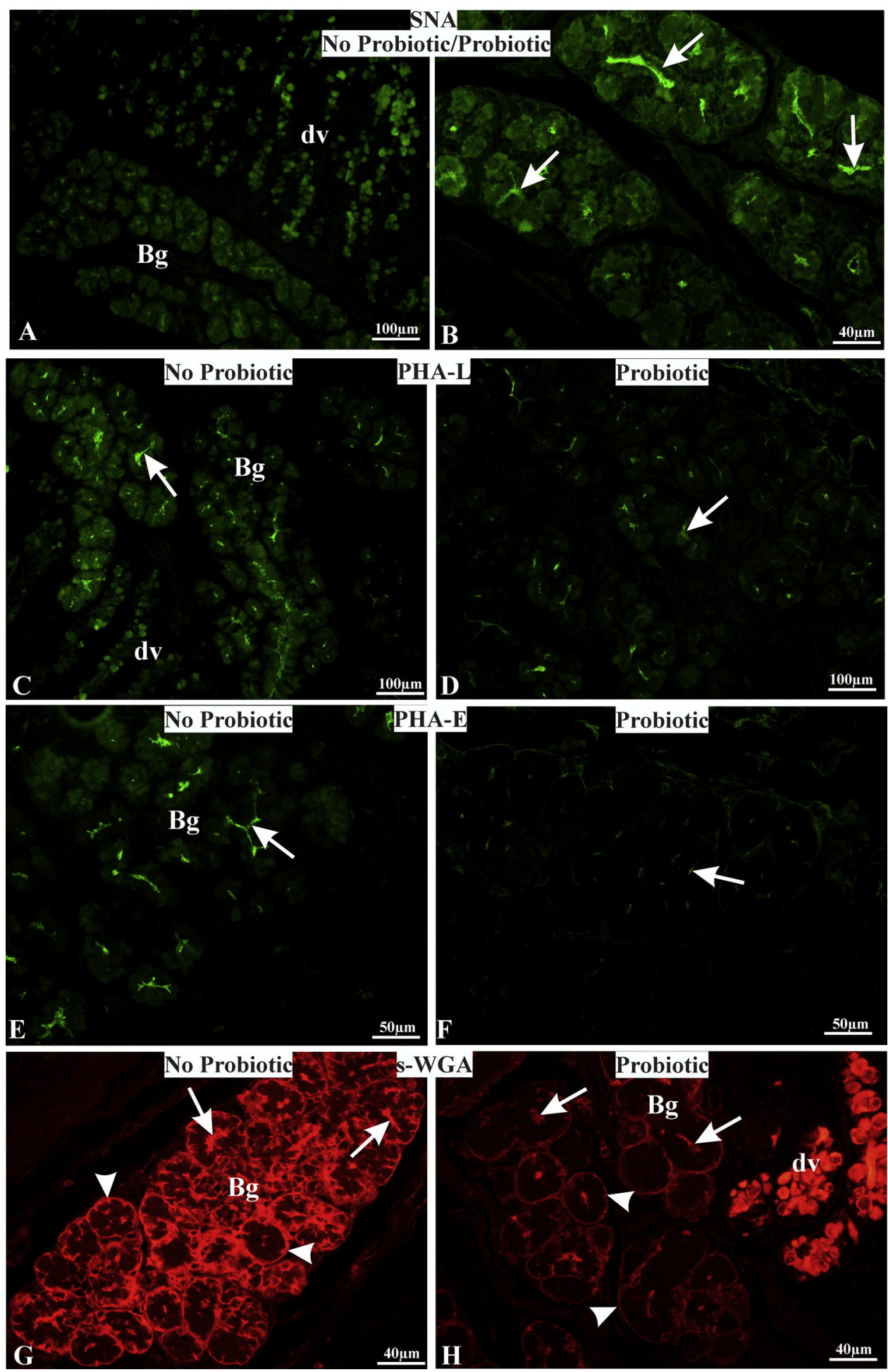

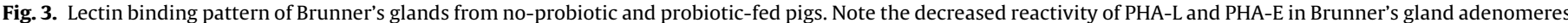

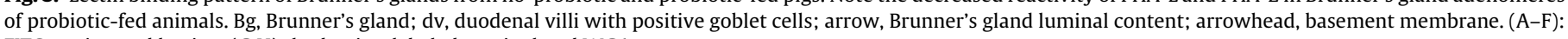
FITC-conjugated lectins; $(\mathrm{G}, \mathrm{H})$ rhodamine-labeled succinylated WGA.

ural antibiotic and as a tumor suppressor for differentiated-type adenocarcinoma (Nakayama, 2014).

The probiotic blend induced a great change in the glycosylation pathway of the epithelium of Brunner's glands. Conventional histochemistry showed a drastic reduction in neutral mucins and the primary presence of carboxyl acidic glycoproteins. In addition, lectin histochemistry revealed a reduction in high mannose (Con A) and $\alpha 1,2$-linked fucosylated glycans (UEA I) and the disappear- ance of complex types of $\mathrm{N}$-glycans (PHA-L, PHA-E) terminating with lactosamine $\left(\mathrm{RCA}_{120}\right)$ and fucosylated oligomers binding LTA, as well as O-linked glycans terminating with Gal $\beta 1,3 \mathrm{GalNAc}$ (PNA) and terminal galactose (GSA I-B ${ }_{4}$ ). Moreover, the luminal content of Brunner's glands exhibited a reduced amount of bisecting GlcNAc- and Gal-bearing glycoproteins (PHA-E) when compared with that from probiotic-fed pigs. However, the dietary probiotic complex increased the synthesis of the most common mucin-type 

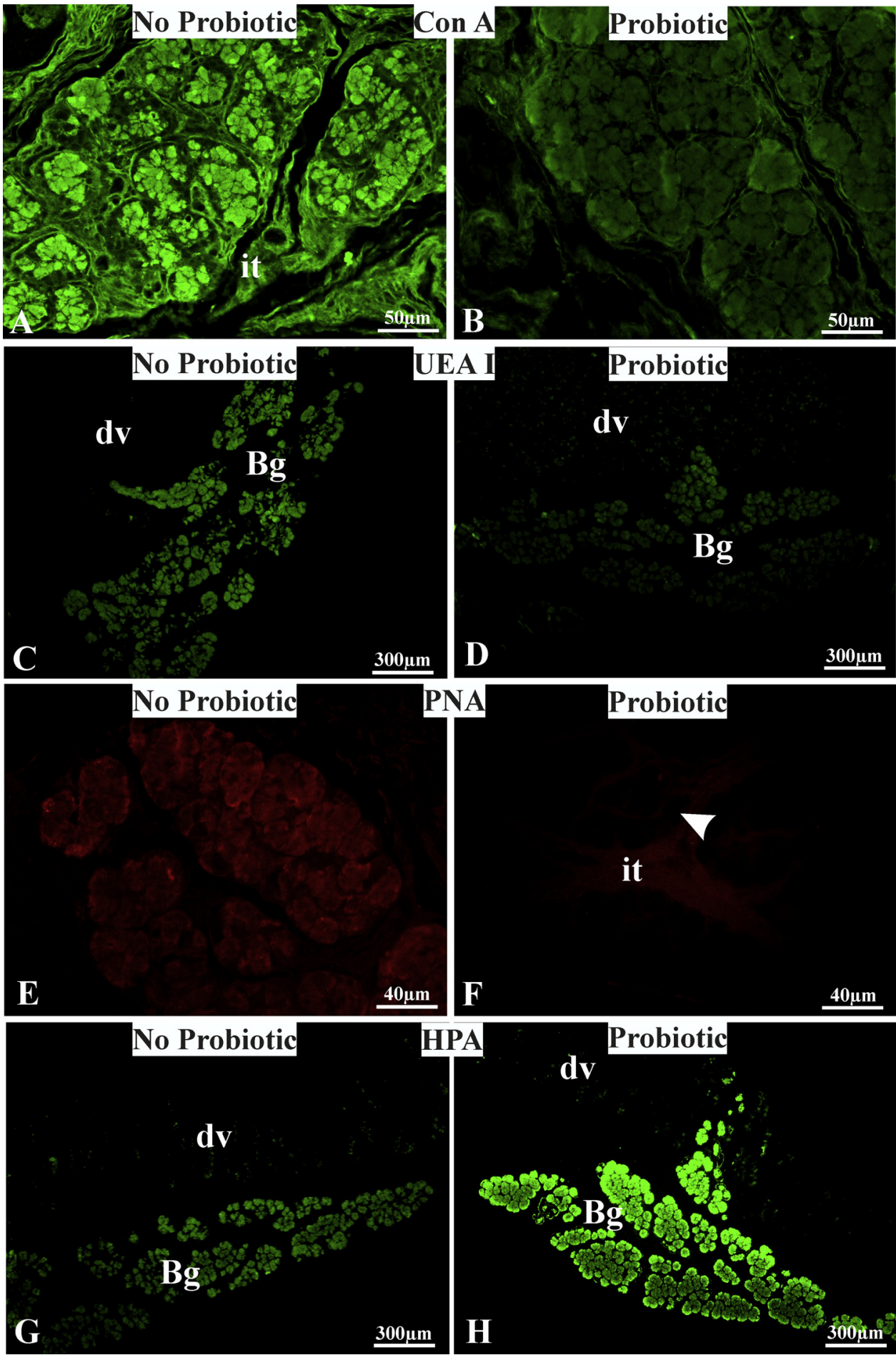

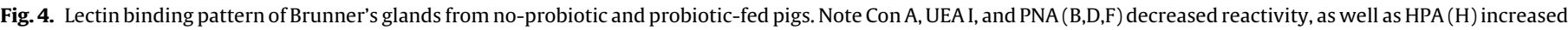

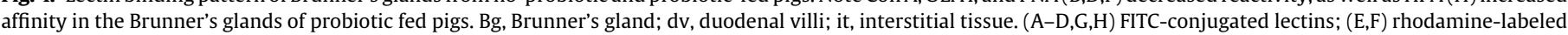
PNA.

O-linked glycans terminating with GalNAc (HPA). These findings are in line with the evidence that components of the diet and the gut microflora are in contact within the intestinal tract and that dietary composition may influence the carbohydrate structures of the mucosal and mucin glycoconjugates with marked consequences for the adherence of microflora and for the gut itself (Kelly et al., 1992). Some studies demonstrated that pre-treatment with probiotics increased the expression of MUC2, MUC5AC, and MUC6 in rat stomach (Caballero-Franco et al., 2007; Lam et al., 2007;
Gomi et al., 2013). Moreover, experimental evidence supports the hypothesis of the adaptability of Brunner's gland mucins to dietary changes (Krause, 2000; Desantis et al., 2011).

In conclusion, this study demonstrates that probiotic supplementation affects the glycan composition of the mucins produced in the Brunner's glands of growing-finishing pigs. Since probiotics have a stimulating effect on digestive processes and the immune system of pigs (Meng et al., 2010; Hu et al., 2015; Liu et al., 2017) and the probiotic blend induced higher growth performance and 
meat quality than did the control basal diet (Tufarelli et al., 2017), we believe that the observed changes in the composition of the secretory mucins from Brunner's glands could act effectively on the gastrointestinal function and health status of animals. However, further studies are necessary to understand the mechanism of probiotic action on the glycosylation pathway of the mucins secreted by Brunner's glands.

\section{References}

Aigner, B., Renner, S., Kessler, B., Klymiuk, N., Kurome, M., Wünsch, A., Wolf, E., 2010. Transgenic pigs as models for translational biomedical research. J. Mol. Med. Berl. Ger. 88, 653-664.

Bartman, A.E., Buisine, M.P., Aubert, J.P., Niehans, G.A., Toribara, N.W., Kim, Y.S., Kelly, E.J., Crabtree, J.E., Ho, S.B., 1998. The MDC6 secretory mucin gene is expressed in a wide variety of epithelial tissues. J. Pathol. 186, 398-405.

Becker, D.J., Lowe, J.B., 2003. Fucose: biosynthesis and biological function in mammals. Glycobiology 13, 41R-53R.

Büsing, K., Zeyner, A., 2015. Effects of oral Enterococcus faecium strain DSM 10663 NCIMB 10415 on diarrhoea patterns and performance of sucking piglets. Benef. Microbes 6, 41-44.

Caballero-Franco, C., Keller, K., De Simone, C., Chadee, K., 2007. The VSL\#3 probiotic formula induces mucin gene expression and secretion in colonic epithelial cells. Am. J. Physiol. Gastrointest. Liver Physiol. 292, G315-G322.

Collaco, A.M., Jakab, R.L., Hoekstra, N.E., Mitchell, K.A., Brooks, A., Ameen, N.A., 2013. Regulated traffic of anion transporters in mammalian Brunner's glands: a role for water and fluid transport. Am. J. Physiol. Gastrointest. Liver Physiol. 305, G258-G275.

Desantis, S., Zizza, S., Accogli, G., Tufarelli, V., Laudadio, V., 2011. Morphometric features and glycoconjugate pattern of rabbit intestine are affected by particle size of pelleted diets. Anat. Rec. 294, 1875-1889.

Flemstrom, G., Isenberg, J.I., 2001. Gastroduodenal mucosal alkaline secretion and mucosal protection. News Physiol. Sci. 16, 23-28.

Florey, H.W., Harding, H.E., 1933. The function of Brunner's glands and pyloric glands of the stomach. J. Pathol. Bacteriol. 37, 431-453.

Fuller, R., 2006. Reasons for the apparent variation in the probiotic response. Biologia, Bratislava 61, 751-754.

Gelberg, H., Whiteley, H., Ballard, G., Scott, J., Kuhlenschmidt, M., 1992. Temporal lectin histochemical characterization of porcine small intestine. Am. J. Vet. Res. 53, 1873-1880.

Gomi, A., Harima-Mizusawa, N., Shibahara-Sone, H., Kano, M., Miyazaki, K., Ishikawa, F., 2013. Effect of Bifidobacterium bifidum BF-1 on gastric protection and mucin production in an acute gastric injury rat model. J. Dairy Sci. 96, 832-837.

Gonzalez, L.M., Moeser, A.J., Blikslager, A.T., 2015. Porcine models of digestive disease: the future of large animal translational research. Transl. Res. 166, 12-27.

Guilloteau, P., Zabielski, R., Hammon, H.M., Metges, C.C., 2010. Nutritional programming of gastrointestinal tract development. Is the pig a good model for man? Nutr. Res. Rev. 23, 4-22.

Heinritz, S.N., Mosenthin, R., Weiss, E., 2013. Use of pigs as a potential model for research into dietary modulation of the human gut microbiota. Nutr. Res. Rev. 26, 191-209.

Hu, Y., Dun, Y., Li, S., Zhang, D., Peng, N., Zhao, S., Liang, Y., 2015. Dietary Enterococcus faecalis LAB31 improves growth performance, reduces diarrhea, and increases fecal Lactobacillus number of weaned piglets. PLoS One 10, e0116635.

Kelly, D., Begbie, R., King, T.P., 1992. Postnatal intestinal development. In: Varley, M.A., Williams, P.E.V., Lawrence, T.L.J. (Eds.), Neonatal Survival and Growth. Occasional Publication No. 15, British Society of Animal Production, Edinburgh, UK, pp. 63-79.

Krause, W.J., 2000. Brunner's glands: a structural, histochemical and pathological profile. Prog. Histochem. Cytochem. 35, 255-367.
Lam, E.K., Tai, E.K., Koo, M.W., Wong, H.P., Wu, W.K., Yu, L., So, W.H., Woo, P.C., Cho, C.H., 2007. Enhancement of gastric mucosal integrity by Lactobacillus rhamnosus GG. Life Sci. 80, 2128-2136.

Lehmann, F., Tiralongo, E., Tiralongo, J., 2006. Sialic acid-specific lectins: occurrence specificity and function. Cell. Mol. Life Sci. 63, 1331-1354.

Liquori, G.E., Mastrodonato, M., Mentino, D., Scillitani, G., Desantis, S., Portincasa, P., Ferri, D., 2012. In situ characterization of O-linked glycans of Muc2 in mouse colon. Acta Histochem. 114, 723-732.

Liu, C., Zhu, Q., Chang, J., Yin, Q., Song, A., Li, Z., Wang, E., Lu, F., 2017. Effects of Lactobacillus casei and Enterococcus faecalis on growth performance: immune function and gut microbiota of suckling piglets. Arch. Anim. Nutr. 71, 120-133.

Mc Manus, J.F.A., 1948. Histological and histochemical uses of periodic acid. Stain Technol. 23, 99-108.

Meng, Q.W., Yan, L., Ao, X., Zhou, T.X., Wang, J.P., Lee, J.H., Kim, I.H., 2010. Influence of probiotics in different energy and nutrient density diets on growth performance, nutrient digestibility, meat quality, and blood characteristics in growing-finishing pigs. J. Anim. Sci. 88, 3320-3326.

Nakayama, J., 2014. Dual roles of gastric gland mucin-specific O-glycans in prevention of gastric cancer. Acta Histochem. Cytochem. 47, 1-9.

NRC, 1998. Nutrient Requirements of Swine, 10 th rev. ed. National Academies Press, Washington, DC, pp. 110-142.

Oelschlaeger, T.A., 2010. Mechanisms of probiotic actions - a review. Int. J. Med. Microbiol. 300, 57-62.

Pearse, A.G.E., 1968. Histochemistry Theoretical and Applied, vol. I., 3rd ed. Churchill, London.

Perez-Vilar, J., Hill, R.L., 1999. The structure and assembly of secreted mucins. J. Biol. Chem. 274, 31751-31754.

Prather, R.S., Lorson, M., Ross, J.W., Whyte, J.J., Walters, E., 2013. Genetically engineered pig models for human diseases. Annu. Rev. Anim. Biosci. 1, 203-219.

Ralston, K.S., Petri Jr., W.A., 2011. Tissue destruction and invasion by Entamoeba histolytica. Trends Parasitol. 27, 254-263.

Schauer, R., 2004. Sialic acids: fascinating sugars in higher animals and man. Zoology $107,49-64$.

Schumacher, U., Duku, M., Katoh, M., Jorns, J., Krause, W.J., 2004. Histochemica similarities of mucins produced by Brunner's glands and pyloric glands: a comparative study. Anat. Rec. A: Discov. Mol. Cell. Evol. Biol. 278, 540-550.

Scillitani, G., Mentino, D., 2015. Comparative glycopattern analysis of mucins in the Brunner's glands of the guinea-pig and the house mouse (Rodentia). Acta Histochem. 117, 612-623.

Sharon, N., Lis, H., 2004. History of lectins: from hemagglutinins to biological recognition molecules. Glycobiology 14, 53R-62R.

Spicer, S.S., 1965. Diamine methods for differentialing mucosubstances histochemically. J. Histochem. Cytochem. 13, 211-234.

Spicer, S.S., Schulte, B.A., 1992. Diversity of cell glycoconjugates shown histochemically: a perspective. J. Histochem. Cytochem. 40, 1-38.

Stramandinoli-Zanicotti, R.T., Carvalho, A.L., Rebelatto, C.L.K., Sassi, L.M., Torres, M.F. Senegaglia, A.C., Boldrinileite, L.M., Correa-Dominguez, A., Kuligovsky, C., Brofman, P.R.S., 2014. Brazilian minipig as a large-animal model for basic research and stem cell-based tissue engineering: characterization and in vitro differentiation of bone marrow-derivedmesenchymal stem cells. J. Appl. Oral. Sci. Rev. F.O.B. 22, 218-227.

Takehana, K., Abe, M., 1986. Histochemistry of complex carbohydrates in the duodenal glands in the pig. J. Coll. Dairy. 11, 371-380.

Toribara, N.W., Ho, S.B., Gum, E., Gum Jr, J.R., Lau, P., Kim, Y.S., 1997. The carboxylterminal sequence of the human secretory mucin MUC6. Analysis of the primary amino acid sequence. J. Biol. Chem. 272, 16398-16403.

Tufarelli, V., Crovace, A.M., Rossi, G., Laudadio, V., 2017. Effect of a dietary probiotic blend on performance, blood characteristics, meat quality and faecal microbial shedding in growing-finishing pigs. S. Afr. J. Anim. Sci. 47, 875-882.

Verdiglione, R., Mammola, C.L., Filotto, U., 2002. Glycoconjugatehistochemistry of bovine Brunner's glands. Ann. Anat. 184, 61-69.

Verma, N., Rettenmeier, A.W., Schmitz-Spanke, S., 2011. Recent advances in the use of Sus scrofa (pig) as a model system for proteomic studies. Proteomics 11, 776-793. 